Available online at http://jurnal.goretanpena.com/index.php/JSSR

\title{
MODEL PEMBELAJARAN MATEMATIKA DALAM PERSPEKTIF FILSAFAT PENDIDIKAN (SEBUAH KAJIAN AKSIOLOGI)
}

\author{
Nilam Sari ${ }^{1,2}$, Dian Armanto ${ }^{1}$, Anim ${ }^{1,3}$ \\ ${ }^{1}$ Pascasarjana Pendidikan Matematika, Universitas Negeri Medan \\ ${ }^{2}$ Pendidikan Matematika, Universitas Quality Medan \\ ${ }^{3}$ Pendidikan Matematika, Universitas Asahan \\ Email:1,2nilamsarie@gmail.com, ${ }^{1}$ dianarmanto@unimed.ac.id, \\ 1,3animfaqot30031991@gmail.com,
}

\begin{abstract}
The purpose of this paper is to discuss the learning model, especially in learning mathematics in secondary schools from the point of view of the philosophy of education. The problem raised in this paper is how to model mathematics learning in the perspective of educational philosophy in terms of axiological studies. The axiology study here covers what the mathematics learning model is made for?, why the learning model is needed and how to apply the learning model in secondary schools. This paper uses library research, with a qualitative approach. The results of the discussion of this paper can be concluded: 1. The application of the learning model in schools aims as a means for teachers and students to achieve the goals of learning and as a guide in the implementation of the syntax that has been designed with the aim that learning is directed to the final stage of learning. 2. Learning models are needed in the teaching and learning process in the classroom. because by applying the learning model the interaction between teachers and students becomes meaningful, meaning that every process carried out in learning activities supports the achievement of the objectives of the learning itself. research that has been done that in the application of appropriate learning models can improve students' ability in mathematics, especially in solving contextual problems

Keywords: Philosophy of education, learning models, axiology
\end{abstract}

\begin{abstract}
Abstrak: Tujuan dari tulisan ini adalah untuk membahas tetang model pembelajaran khususnya dalam pembelajaran matematika di sekolah menengah yang ditinjau dari sudut pandang filsafat pendidikan. Permasalahan yang diangkat pada tulisan ini yakni bagaimana model pembelajaran matematika dalam perpesktif filsafat pendidikan ditinjau dari kajian aksiologi. Kajian aksiologi disini meliputi tentang untuk apa model pembelajaran matematika dibuat?, mengapa model pembelajaran itu diperlukan dan bagaimana menerapkan model pembelajaran tersebut pada sekolah menengah. Tulisan ini menggunakan kajian pustaka (library research), dengan pendekatan kualitatif. Adapun hasil pembahasan tulisan ini dapat disimpulkan :1. Penerapan model pembelajaran di sekolah bertujuan sebagai sarana bagi guru dan siswa dalam mencapai tujuan dari pembelajaran dan sebagai pedoman dalam pelaksanaan sintaks yang telah dirancang dengan tujuan agar pembelajaran menjadi terarah sampai pada tahap akhir pembelajaran.2.Model pembelajaran sangat dibutuhkan dalam proses belajar mengajar di kelas karena dengan menerapkan model pembelajaran interaksi antara guru dan siswa menjadi bermakna artinya setiap proses yang dilakukan dalam kegiatan pembelajaran mendukung untuk tercapainya tujuan dari pembelajaran itu sendiri.3.Penerapan model pembelajaran dapat disesuaikan dengan sintaks pembelajaran yang berhubungan dengan karakteristik siswa dan materi pelajaran dimana dari hasil penelitian yang pernah dilakukan bahwa dalam penerapan model pembelajaran yang sesuai dapat meningkatkan kemampuan siswa dalam bermatematika khususnya dalam menyelesaikan masalahmasalah kontekstual.
\end{abstract}

Kata kunci:Filsafat pendidikan, model pembelajaran, aksiologi 
Available online at http://jurnal.goretanpena.com/index.php/JSSR

\section{PENDAHULUAN}

Tujuan Pembelajaran Matematika Berdasarkan Kurikulum Tingkat Satuan Pendidikan (KTSP) yaitu bahwa siswa harus memiliki kemampuan memecahkan masalah. yang meliputi kemampuan memahami masalah, merancang model matematika, menyelesaikan model dan menafsirkan solusi yang diperoleh (Depdiknas, 2006).

Dalam pembelajarna matemtika sangat dibutuhkan model pembelajaran agar proses belajar mengajar dapat berjalan dengan baik sesuai dengan yang diharapkan. Model pembelajaran adalah kerangka konseptual yang melukiskan prosedur sistematis dalam mengorganisasikan pengalaman belajar untuk mencapai tujuan belajar tertentu (Indrawati, 2011). Model pembelajaran memiliki peran sebagai pedoman dalam kegiatan belajar mengajar dikelas.

Ada begitu banyak model pembelajarn yang dapat digunakan dalam pembelajaran matematika, pada umumnya model-model tersebut menuntut siswa untuk terlibat aktif dan bersifat kontekstual. Berikut ini dipaparkan beberapa model yang biasa dilakukan dalam mengajar matematika di sekolah menengah yakni:

1. Model Problem Based Learning.

2. Model Pembelajaran Inkuiri Terbimbing.

3. Model Pembelajaran Kontekstual.

4. Model Realistic Mathematics Education.

5. Model Pembelajarn Open Ended.

6. Model Pembelajaran Eksploratif.

7. Model Pembelajaran SomanticAuditory-Visualization-Intellectually (SAVI).

8. Model Pembelajaran Generatif.

9. Model Pembelajaran Means Ends Analysis (MEA).

10.Model Project-Based Learning

11.Model Pembelajaran Investigasi Matematika.
12.Model Pembelajaran Student Team Achievement Division (STAD).

13.Model Pembelajaran Missouri Mathematics Project (MMP).

14.Model Pembelajaran Kooperatif.

15.Model Situation Based Learning (SBL).

16.Model Pembelajaran Teams-Games Tournament (TGT).

17. Model Pembelajaran creative Problem Solving (CPS).

18. Model Pembelajaran Think Talk Write (TTW).

19.Model Pembelajaran Think Pair Share (TPS).

20.Model Pembelajaran Role Playing.

21.Model Pembelajaran Induktif.

22.Model Pembelajaran Double-Loop Problem Solving (DLPS).

Model -model pembelajaran tersebut sangat erat kaitannya teori pendidikan, karena model pembelajarn merupakan hal mendasar dalam menyusun kurikulum pembelajaran.

Di Indonesia, falsafah/pandangan hidup bangsa yang berlaku adalah pancasila. Maka dibentuk lah kurikulum pendidikan yang memuat nilai-nilai pancasila yang ada dalam setiap aspek pada kurikulum nasional dan model pembelajaran, dimanahasil yang diharapkan dari pendidikan di Indonesia harus mencermikan nilai-nilai yang ada pada setiap butir sila di pancasila.

Filsafat pendidikan adalah filsafat yang digunakan dalam studi mengenai masalah-masalah pendidikan. Filsafat akan menentukan "mau dibawa kemana" siswa kita. Filsafat merupakan perangkat nilai-nilai yang melandasi dan membimbing ke arah pencapaian tujuan pendidikan (muhammad kristiawan, 2016). Pendidikan adalah upaya mengembangkan potensi manusiawi peserta didik baik potensi fisik, potensi cipta, rasa, maupun karsanya, agar potensi itu menjadi nyata dan dapat berfungsi dalam perjalanan hidupnya. Undangundang No. 20 tahun 2003 menyatakan bahwa pendidikan adalah usaha sadar dan 
Available online at http://jurnal.goretanpena.com/index.php/JSSR

terencana untuk mewujudkan suasana belajar dan proses pembelajaran agar peserta didik secara aktif mengembangkan potensi dirinya untuk memiliki kekuatan spiritual keagamaan, pengendalian diri, kepribadian, kecerdasan, akhlak mulia, serta keterampilan yang diperlukan dirinya, masyarakat, bangsa dan Negara(Masyarakat, 2013).

Tujuan filsafat pendidikan adalah memberikan inspirasi bagaimana mengorganisasikan proses pembelajaran yang ideal. Teori pendidikan bertujuan menghasilkan pemikiran tentang kebijakan dan prinsip-prinsip pendidikan yang didasari oleh filsafat pendidikan. Praktik pendidikan atau proses pendidikan menerapkan serangkaian kegiatan berupa implementasi kurikulum dan interaksi antara guru dengan peserta didik guna mencapai tujuan pendidikan dengan menggunakan ramburambu dari teoriteori pendidikan. Peranan filsafat pendidikan memberikan inspirasi, yakni menyatakan tujuan pendidikan Negara bagi masyarakat, memberikan arah yang jelas dan tepat dengan mengajukan pertanyaan tentang kebijakan pendidikan dan praktik di lapangan dengan menggunakan rambu-rambu dari teori pendidik. Seorang guru perlu menguasai konsep-konsep yang akan dikaji serta pedagogi atau ilmu mengajar materi subjek terkait, agar tidak terjadi salah konsep atau miskonsepsi pada diri peserta didik.

Beberapa aliran filsafat pendidikan yang berpengaruh dalam pengembangan pendidikan, misalnya, idealisme, realisme, pragmatisme, humanisme, behaviorisme, dan konstruktivisme(Adib, 2015).

Aksiologi adalah cabang filsafat yang mempersoalkan penilaian atau yang berhubungan dengan nilai guna. Gagasan mengenai aksiologi dipelopori oleh Lozte, kemudian Brentano, Husserl, Scheller dan Nicolai Hatmann (Adib, 2015). Menurut Scheller ada dua bidang yang paling populer terkait penilaian yaitu tingkah laku dan keadaan atau tampilan fisik, sehingga aksiologi dibagi dalam 2 jenis yaitu etika dan estetika.

Aksiologi, selain membahas etika dan estetika, juga meliputi hakikat penilaian kebenaran, kebaikan, keindahan dan kesucian. Apapun pendapat para ahli, kita tidak harus mengikutinya, yang terpenting adalah pengakuan atas alasannya. Aksiologi: untuk apa, mengapa dan kaidah dalam pemanfaatan ilmu demi kemaslahatan manusia (penggunaan Ilmu).

Model-model pembelajarn matematika dalam perspektif filsafat pendidikan ditinjau dari kajian aksiologi pada tulisan ini akan dibahas tentang untuk apa model pembelajaran matematika dibuat?, mengapa model pembelajaran itu diperlukan dan bagaimana menerapkan model pembelajaran tersebut pada sekolah menengah.

\section{METODE}

Adapun ada metode pengumpulan data yang digunakan dalam penelitian ini adalah dokumentasi maupun studi literatur. Jenis data yang digunakan adalah data sekunder, yaitu data pendukung yang bersumber dari literatur maupun referensi-referensi yang ada. Selain itu, dilakukan juga pengumpulan dokumen atau data-data yang dianggap penting untuk keperluan penelitian.

\section{HASIL DAN PEMBAHASAN}

Adapun pembahasan meliputi
hal-hal terkait dengan model
pembelajaran yang dilakukan dalam
pembelajaran matematika di kelas.
Pembahasan yang pertama terkait tujuan
model pembelajaraan bagi guru dan siswa
pada penerapan proses belajar mengajar.
Model pembelajaran adalah suatu rencana
atau pola yang dapat digunakan untuk
membentuk kurikulum (rencana


Available online at http://jurnal.goretanpena.com/index.php/JSSR

pembelajaran), sehingga kegiatan belajar mengajar lebih baik. Dengan menggunakan model pembelajaran dengan baik maka kita akan tau model yang telah didesain oleh guru yang diterapkan ke siswa maka, kita akan tahu sifat siswa dapat diketahui kekurangan dan kelebihan model yang telah di desain oleh guru.(Khoerunnisa \& Aqwal, 2020). Model pembelajaran merupakan salah satu komponen pembelajaran yang menjadi panduan dalam langkah-langkah kegiatan di kelas. Langkah-langkah dalam pembelajaran dinamakan sintaks yang dapat dikembangkan sesuai dengan situasi dan kondisi di kelas terkait dengan kebutuhan pembelajaran itu sendiri, misalnya materi yang diajarkan, lingkungan belajar dan karakteristik siswa dilingkungan tersebut. Terkait dengan hal tersebut kemampuan guru dalam memahami lingkungan dan karakteristik siswa dan materi menjadi hal yang sangat penting dalam menunjang keberhasilan pembeleajaran di kelas. Jika guru sudah dapat memahami hal tersebut maka akan dengan mudah merancang sebuah pembelajaran dengan menggunakan model pembelajaran. Jika hal ini sudah dilakukan maka guru akan dengan mudah menerapkan sintaks pembelajaran yang terfokus pada tujuan akhir pembelajaran (Isrok'atun, 2019).

Adapun fungsi model pembelajaran adalah: a) Pedoman bagi para perancang pembelajaran dan para pengajar dalam merencanakan kegiatan pembelajaran. b) Pedoman bagi dosen/ guru dalam melaksanakan pembelajaran sehingga dosen/guru dapat menentukan langkah dan segala sesuatu yang dibutuhkan dalam pembelajaran tersebut. c) Memudahkan para dosen/guru dalam membelajarkan para muridnya guna mencapai tujuan yang ditetapkannya. d) Membantu peserta didik memperoleh informasi, ide, ketrampilan, nilai-nilai, cara berfikir, dan belajar bagaimana belajar untuk mencapai tujuan pembelajaran (Asyafah, 2019).
Model digunakan guna membantu memperjelas prosedur pada saat guru mengajar, untuk menciptakan hubungan serta keadaan keseluruhan dari apa yang didesain dalam pembelajaran.

Jadi dapat disimpulkan tujuan dari penerapan model pembelajaran ini adalah sebagai sarana bagi guru dan siswa dalam mencapai tujuan dari pembelajaran dan model pembelajaran sebagai pedoman dalam pelaksanaan sintaks yang telah dirancang dengan tujuan agar pembelajaran menjadi terarah sampai pada tahap akhir pembelajaran.

Untuk menjawab persoalan selanjutnya terkait mengapa dibutuhkan model pembelajaran dalam proses belajar mengajar di kelas? Sebelumnya kita akan membahas apa sebenarnya peran model pembelajaran dalam kegiatan pembelajaran. Berikut ini ada beberapa peran model pembelajaran di sekolah:

1. Membantu guru menciptakan perubahan perilaku siswa yang di inginkan

2. Membantu guru dalam menentukan cara dan sarana untuk menciptakan lingkungan yang sesuai dalam melaksanakan pembelajaran

3. Membantu menciptakan interaksi Antara Guru dan peserta didik yang di inginkan selama proses pembelajaran berlangsung.

4. Membantu guru dalam mengkontruksi kurikulum, silabus atau konten pelajaran

5. Membantu guru atau infrastruktur dalam memilih materi pembelajaran yang tepar untuk mengajar yang disiapkan daldam kurikulum

6. Membantu guru dalam merancang kegiatan pendidikan atau pembeleajaran yang sesuai

7. Memberikan bahan prosedur untuk mengembangkan materi dan sumber belajar yang menarik dan efektif

8. Merangsang pengembangan inovasi pendidikan atau pembelajaran baru 
Available online at http://jurnal.goretanpena.com/index.php/JSSR

9. Membantu mengkomunikasikan informasi tentang teori mengajar

10.Membantu membangun hubungan Antara belajar dan mengajar secara empiris (Isrok'atun, 2019)

Ada beberapa alasan pentingnya pengembangan model pembelajaran, yaitu: a) model pembelajaran yang efektif sangat membantu dalam proses pembelajaran sehingga tujuan pembelajaran lebih mudah tercapai, b) model pembelajaran dapat memberikan informasi yang berguna bagi peserta didik dalam proses pembelajarannya, c) variasi model pembelajaran dapat memberikan gairah belajar peserta didik, menghindari rasa bosan, dan akan berimplikasi pada minat serta motivasi peserta didik dalam mengikuti proses pembelajaran, d) mengembangkan ragam model pembelajaran sangat urgen karena adanya perbedaan karakteristik, kepribadian, kebiasaan-kebiasaan cara belajar para peserta didik, e) kemampuan dosen/guru dalam menggunakan model pembelajaran pun beragam, dan mereka tidak terpaku hanya pada model tertentu, dan f) tuntutan bagi dosen/guru profesional memiliki motivasi dan semangat pembaharuan dalam menjalankan tugas/profesinya (Khoerunnisa \& Aqwal, 2020).

Jadi dapat disimpulkan bahwa model pembelajaran sangat dibutuhkan dalam proses belajar mengajar di kelas karena dengan menerapkan model pembelajaran interaksi antara guru dan siswa menjadi bermakna artinya setiap proses yang dilakukan dalam kegiatan pembelajaran mendukung untuk tercapainya tujuan dari pembelajaran itu sendiri.

Pembahasan yang ketiga tentang bagaimana menerapkan model-model pembelajaran di sekolah menengah ?

Ada begitu banyak artikel tentang contohcontoh penerapan model pembelajaran di sekolah. Namun yang akan diuraikan pada pembahasan kali ini hanya 5 contoh penerapan model pembelajaran dalam pelaksanaan pembelajaran matematika di sekolah menengah yakni:

\section{Penerapan Problem Based Learning (PBL)}

Problem Based Learning (pembelajaran berbasis masalah) adalah suatu pendekatan pembelajaran yang menggunakan masalah dunia nyata sebagai suatu konteks bagi siswa untuk belajar tentang cara berfikir kritis dan keterampilan pemecahan masalah, serta untuk memperoleh pengetahuan dan konsep yang esensial dari materi pelajaran Penerapan model Problem based learning melalui beberapa tahapan pelaksanaan (Sintaks) diantaranya terlihat pada table berikut:

\begin{tabular}{|c|l|}
\hline No & \multicolumn{1}{|c|}{$\begin{array}{c}\text { Langkah-Langkah PBL } \\
\text { (Sintaks) }\end{array}$} \\
\hline 1 & Orientasi Siswa pada masalah \\
\hline 2 & mempesiapkan siswa untuk belajar \\
\hline 3 & $\begin{array}{l}\text { Membimbing proses penyesesaian } \\
\text { masalah baik individu atau } \\
\text { kelompok }\end{array}$ \\
\hline 4 & $\begin{array}{l}\text { menyajikan hasil penyelesaian } \\
\text { masalah }\end{array}$ \\
\hline 5 & $\begin{array}{l}\text { Analisisdan evaluasi proses } \\
\text { penyelesaian masalah }\end{array}$ \\
\hline
\end{tabular}

(Nilam Sari, 2019).

Dalam pelaksanaan pembelajaran dengan penerapan problem based learning menurut hasil penelitian ,(Maryati, 2018; Nilam Sari, 2019) menunjukkan bahwa selalu ada peningkatan baik hasil belajar ataupun kemampuan siswa dalam bermatematika.

2. Penerapan Pembelajaran Project-Based Learning

Model project-based learning merupakan salah satu model pembelajaran aktif yang berorientasi pada project. Dalam 
Available online at http://jurnal.goretanpena.com/index.php/JSSR

penerapan dilapangan model ini melali 3 tahapan proses yang dapat dilihat pada table berikut:

\begin{tabular}{|l|l|}
\hline No & \multicolumn{1}{|c|}{$\begin{array}{c}\text { Langkah-Langkah PJBL } \\
\text { (Sintaks) }\end{array}$} \\
\hline 1 & Planning (Perencanaan) \\
\hline 2 & Creating (Implementasii) \\
\hline 3 & Processing (Pengolahan) \\
\hline
\end{tabular}

(Isrok'atun, 2019).

Beberapa hasil penelitian tentang penerapan model project based learning (Murniarti, 2017; Rofifah, 2020) memperoleh hasil bahwa dengan menerapkan project based learning dapat membuat siswa menjadi lebih aktif, inovatif dan meningkatkan kreatifitas siswa dalam belajar.

\section{Penerapan Realistic Mathematics Education (RME)}

Ide utama dari RME adalah bahwa siswa harus diberi kesempatan untuk menemukan kembali (reinvent) ide dan konsep matematika dengan bimbingan orang dewasa melalui penjelajahan berbagai situasi dan persoalanpersoalan dunia nyata atau real world (Astuti, 2018) Adapun sintaks dari model RME ini diuraikan dalam table berikut

\begin{tabular}{|l|lr|}
\hline No & \multicolumn{1}{|c|}{$\begin{array}{c}\text { Langkah-Langkah RME } \\
\text { (Sintaks) }\end{array}$} \\
\hline 1 & \multicolumn{1}{|c|}{ Memahami masalah kontekstual } \\
\hline 2 & Menjelaskan masalah kontekstual \\
\hline 3 & $\begin{array}{l}\text { Menyelesaikan masalah } \\
\text { kontekstual }\end{array}$ \\
\hline 4 & $\begin{array}{l}\text { Membandingkan dan } \\
\text { mendiskusikan Jawaban }\end{array}$ \\
\hline 5 & Menyimpulkan \\
\hline
\end{tabular}

(Isrok'atun, 2019)

Dari beberapa hasil penelitian tentang RME ini memperoleh hasil bahwa dengan penerapan pembelajaran dengan model RME dapat berpengaruh positif pada siswa khusunya pada kemampuan pemecahan masalah siswa. Sedangkan hasil penelian (Artika et al., 2019) bahwa
RME dapat digunakan guru sebagai salah satu model pembelajaran alternatif, karena model tersebut merupakan model yang menarik dan mudah diterapkan khususnya pada mata pelajaran matematika sebab model ini mengacu berdasarkan pengalaman siswa dan benda-benda nyata atau konkrit.

\section{Penerapan Model Situation Based learning (SBL)}

Model Situation Based learning (SBL) merupakan model pembelajaran kontruktivisme untuk membangun konsep dengan mempelajari apa yang terkandung dalam suatu situasi.

Dalam penerapannya model ini melaui beberapa tahapan diantaranta terlihat dalam table berikut(Isrok'atun, 2019)

\begin{tabular}{|l|l|}
\hline No & \multicolumn{1}{|c|}{$\begin{array}{c}\text { Langkah-Langkah SBL } \\
\text { (Sintaks) }\end{array}$} \\
\hline 1 & Creating Mathematical Situation \\
\hline 2 & Posing mathematical problem \\
\hline 3 & Solving mathematical problem \\
\hline 4 & Applying mathematics \\
\hline
\end{tabular}

Berdasarkan hasil beberapa penelitian tentang Penerapan model pembelajaran Situation Based Learning bahwa model ini dapat menjadi salah satu solusi yang dapat digunakan dalam meningkatkan kemampuan peserta didik dalam memecahkan masalah matematika(Lestari et al., 2019)

\section{Penerapan Model Open Ended}

Pembelajaran open ended adalah suatu pembelajaran yang menyajikan suatu permasalah yang bersifat terbuka kepada siswa. Permasalahan yang disajikan merupakan masalah dengan berbagai alternative jawaban.

Dalam penerapan di kelas model ini mempunyai 5 tahapan/sintak, dapat dilihat pada table berikut.

\begin{tabular}{|l|l|}
\hline No & $\begin{array}{c}\text { Langkah-Langkah(Sintaks) } \\
\text { Open Ended }\end{array}$ \\
\hline 1 & Menyajikan Masalah \\
\hline
\end{tabular}


Available online at http://jurnal.goretanpena.com/index.php/JSSR

\begin{tabular}{|l|l|}
\hline 2 & Mendesain pembelajaran \\
\hline 3 & $\begin{array}{l}\text { Memerhatikan dan mencatat } \\
\text { respon siswa }\end{array}$ \\
\hline 4 & $\begin{array}{l}\text { Membimbing dan mengarahkan } \\
\text { siswa }\end{array}$ \\
\hline 5 & Membuat kesimpulan \\
\hline
\end{tabular}

(Isrok'atun, 2019)

Dari hasil penelitian tentang penerapan model open ended di sekolah menengah bahwa pembelajaran ini dapat meningkatkan kemampuan berpikir kreatif matematik siswa dan dapat meningkatkan hasil belajar siswa (Magelo et al., 2019)

Jadi dari pemaparan di atas dapat disimpulkan terkait penerapan model pembelajaran secara umum bahwa penerapan model pembelajaran dapat disesuaikan dengan sintaks pembelajaran yang berhubungan dengan karakteristik siswa dan materi pelajaran dimana dari hasil penelitian yang pernah dilakukan bahwa dalam penerapan model pembelajaran yang sesuai dapat meningkatkan kemampuan siswa dalam bermatematika khususnya dalam menyelesaikan masalah-masalah kontekstual.

\section{SIMPULAN}

1. Penerapan model pembelajaran di sekolah bertujuan sebagai sarana bagi guru dan siswa dalam mencapai tujuan dari pembelajaran dan sebagai pedoman dalam pelaksanaan sintaks yang telah dirancang dengan tujuan agar pembelajaran menjadi terarah sampai pada tahap akhir pembelajaran.

2. Model pembelajaran sangat dibutuhkan dalam proses belajar mengajar di kelas karena dengan menerapkan model pembelajaran interaksi antara guru dan siswa menjadi bermakna artinya setiap proses yang dilakukan dalam kegiatan pembelajaran mendukung untuk tercapainya tujuan dari pembelajaran itu sendiri

3. Penerapan model pembelajaran dapat disesuaikan dengan sintaks pembelajaran yang berhubungan dengan karakteristik siswa dan materi pelajaran dimana dari hasil penelitian yang pernah dilakukan bahwa dalam penerapan model pembelajaran yang sesuai dapat meningkatkan kemampuan siswa dalam bermatematika khususnya dalam menyelesaikan masalah-masalah kontekstual.

\section{DAFTAR PUSTAKA}

Adib, M. (2015). Filsafat Ilmu; Ontologi, Epistemologi, Aksiologi, dan Logika Ilmu Pengetahuan. In Yogyakarta: Pustaka Pelajar.

Artika, R. V., Sudrajat, R., \& Wijayanti, A. (2019). Pengaruh Model Realistic Mathematics Education (RME) Berbantu Media Kertas Lipat Terhadap Penanaman Konsep Bangun Datar. Jurnal Ilmiah Sekolah Dasar, 3(4), 481. https://doi.org/10.23887/jisd.v3i4.21 784

Astuti, A. (2018). Penerapan Realistic Mathematic Education (Rme) Meningkatkan Hasil Belajar Matematika Siswa Kelas Vi Sd. Jurnal Cendekia : Jurnal Pendidikan Matematika, 2(1), 49-61. https://doi.org/10.31004/cendekia.v2 $\underline{\mathrm{i} 1.32}$

Asyafah, A. (2019). MENIMBANG MODEL PEMBELAJARAN

(Kajian Teoretis-Kritis atas Model Pembelajaran dalam Pendidikan Islam). TARBAWY: Indonesian Journal of Islamic Education, 6(1), 19-32.

https://doi.org/10.17509/t.v6i1.2056 9

Depdiknas. (2006). Buku Saku: Kurikulum Tingkat Satuan Pendidikan (KTSP) Sekolah Menengah Pertama. Jakarta: Direktorat Pembinaan SMP, Ditjen Mandikdasmen, Depdiknas., Rosda, 46. 
Available online at http://jurnal.goretanpena.com/index.php/JSSR

indrawati.2011.

Perencanaan

Pembelajaran Fisika : Model-

Model Pembelajaran

Implementasinya dalam

Pembelajaran Fisika. Jember: Kementerian Pendidikan dan Kebudayaan Universitas Jember.

Isrok'atun. 2019, Model-model Pembelajaran Matematika, cet.2 Jakarta:Bumi Aksara,

Khoerunnisa, P., \& Aqwal, S. M. (2020). Analisis Model-model Pembelajaran. Fondatia, 4(1), 1-27. https://doi.org/10.36088/fondatia.v4i 1.441

Lestari, I., Andinny, Y., \& Mailizar, M. (2019). Pengaruh Model Pembelajaran Situation Based Learning dan Kemandirian Belajar Terhadap Kemampuan Pemecahan Masalah Matematis. JNPM (Jurnal Nasional Pendidikan Matematika), 3(1), 95. https://doi.org/10.33603/jnpm.v3i1.1 748

Magelo, C., Hulukati, E., \& Djakaria, I. (2019). Pengaruh Model Pembelajaran Open-Ended terhadap Kemampuan Berpikir Kreatif Matematik Ditinjau dari Motivasi Belajar. Jambura Journal of Mathematics, 2(1), 15-21. https://doi.org/10.34312/jjom.v2i1.2 593

Maryati, I. (2018). Penerapan Model Pembelajaran Berbasis Masalah Pada Materi Pola Bilangan Di Kelas
Vii Sekolah Menengah Pertama. Mosharafa: Jurnal Pendidikan Matematika, 7(1), 63-74. https://doi.org/10.31980/mosharafa. v7i1.342

Masyarakat, K. (2013). : Undang-Undang Nomor Undang-Undang Nomor.

muhammad kristiawan. (2016). Filsafat 2016.

Murniarti, E. (2017). Penerapan Metode Project Based Learning. Journal of Education, 3(2), 369-380.

Nilam Sari. (2019). Pengaruh Pembelajaran Berbasis Masalah Pada Kemandirian Belajar Matematis SiswaSMK Ar-Rahman Medan. Journal of Chemical Information and Modeling, 53(9), 1689-1699.

Paedagogic, M. (2020). Vol . IV No . 2 , Maret 2020, hlm . $153-162$ DOI: https://doi.org/10.36294/jmp.vxix.xx $x \quad$ Available online www.jurnal.una.ac.id/indeks/jmp MENINGKATKAN HASIL BELAJAR SISWA PADA POKOK BAHASAN BILANGAN PANGKAT DUA DENGAN MODEL PEMBELAJARAN OPEN - ENDED Has. IV(2).

Rofifah, D. (2020). 済無No Title No Title No Title. In Paper Knowledge. Toward a Media History of Documents. 